\title{
Uma experiência em comunicação e saúde
}

Marina Ruiz de Matos ${ }^{1}$

Luiz Carlos Meneguetti ${ }^{2}$

Ana Luisa Zaniboni Gomes ${ }^{3}$

\section{Introdução}

Nas sociedades contemporâneas, uma rede diversificada e complexa de discursos e mensagens circula em velocidade cada vez maior. Todas as instituições, independente da natureza de seus fins, todos os movimentos sociais e grupos de interesse usam estratégias de comunicação que tentam garantir visibilidade diante da avalanche de conteúdos, informações e símbolos dos outros setores.

O Ministério da Saúde, por meio da Secretaria de Gestão Participativa, contatou universidades brasileiras com o interesse de desenvolver alternativas de comunicação em saúde direcionadas às rádios comunitárias. A proposta foi a criação de cursos que ampliassem a informação disponível a esse segmento.

Conforme Pitta e Oliveira (1996), no caso da saúde, por meio da racionalidade do discurso técnico, têm sido buscadas alternativas de comunicação para moldar os comportamentos das camadas populares. Os autores apontam que, com a constitucionalidade adquirida em 1988, os canais de expressão dos Conselhos de Unidades Básicas, Distritais, Municipais e Estaduais abrem-se à possibilidade de incorporar um modelo menos normativo.

Nessa perspectiva, a ideia norteadora do projeto foi a troca de conhecimentos, experiências e sentimentos entre funcionários dos serviços de saúde e comunicadores das rádios comunitárias que gerasse como resultado uma união de esforços na comunicação em saúde com a comunidade. Conforme Valla (1998), para que a comunicação se estabeleça, é necessário construir pontes entre serviço e usuários que permitam chegar a um conhecimento resultante da troca entre vivências desiguais.

O projeto foi elaborado por técnicos do Departamento de Medicina Preventiva da Unifesp (Universidade Federal de São Paulo), da Secretaria da Saúde do Estado de São Paulo, da Secretaria de Saúde do Município de Guarulhos, da Hemeroteca Sindical Brasileira e Oboré Projetos Especiais em Comunicações e Artes.

Teve como local escolhido o município de Guarulhos, componente da área conhecida como Grande São Paulo. Formado por volta de 1560, por iniciativa dos padres da Companhia de Jesus, teve sua denominação atual assumida em 6 de novembro de 1906. Segundo dados da Fundação Sistema Estadual de Análise de Dados-SEADE, atualmente possui cerca de um milhão e duzentos mil habitantes,

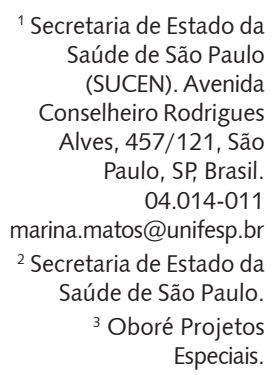
Especiais. 
$98 \%$ dos quais em área urbana. O coeficiente de mortalidade infantil registrado em 2006 foi de 13,99, e a taxa de analfabetismo entre pessoas de 15 anos ou mais era de 6,3\% (dados do Censo Demográfico de 2000). A distribuição de água e coleta de lixo situava-se em patamares acima de $95 \%$, enquanto o serviço de esgoto estava disponível a 77\% dos moradores.

\section{Metodologia}

\section{Definição de estratégias}

Uma das preocupações centrais foi evitar a repetição do modelo pedagógico linear e unidirecional, em que os temas que viessem a ser tratados fossem "ensinados" pelos técnicos aos radialistas. Para isso, optou-se em tratá-los no espaço de vida das pessoas, em seu cotidiano. Domingues (2003), ao recuperar as diferentes correntes teóricas que tratam da vida cotidiana, aborda as dimensões simbólica, material e de poder que ela apresenta e cujas interações se dão em processos, muito específicos e, ao mesmo tempo, abrangentes. No dia-a-dia estão expressos a lógica e os parâmetros utilizados pelos sujeitos para explicarem a si mesmos e as situações que os cercam, com valores compartilhados pelos diferentes segmentos sociais.

Buscou-se um formato de trabalho que desse aos participantes a possibilidade de trazer seus significados para a doença e a saúde e a oportunidade de trocar conhecimentos, afetos e estados de ânimo (Engelmann, 1978). A criação de uma novela permitiu esta junção. Baseada no encontro semanal de duas famílias, "O Almoço de Domingo" permitiu colocar a mesma questão sob o ponto de vista de dois extratos da população. Por meio da fala dos personagens, possibilitou trazer à tona: os problemas da assistência, as normalizações e regras de funcionamento do sistema de saúde, a "compreensão" (tradução) do discurso técnico, o que facilitou a discussão. A novela foi gravada e distribuída para reprodução nas unidades e rádios, acompanhando o material oferecido aos participantes.

Escolheu-se o formato de oficinas, por encaixar-se melhor no processo informação/troca/reflexão/discussão/ação. Decidiu-se por 13 encontros de quatro horas, com os temas dos oito primeiros definidos pela coordenação, outros quatro escolhidos pelos participantes e o último para avaliação (Anexo I).

Elaborou-se material de apoio que, além da radionovela, contou com: excertos de textos acadêmicos, pinturas, charges, caricaturas, músicas, poesias, mensagens, cordéis ou parábolas relacionadas ao tema.

\section{Organização das oficinas}

\section{Seleção dos participantes}

Dos Serviços de Saúde: funcionários de diversas funções (médicos, enfermeiros, dentistas, psicólogos, administrativos e agentes comunitários) dos 33 serviços classificados entre as Unidades Básicas, Unidades de Saúde da Família, Prontos Atendimentos e Unidades Especializadas.

Das Emissoras: $1^{a}$ etapa - Recuperação, no site do Ministério das Comunicações, da lista de rádios autorizadas a funcionarem no município e dos pedidos de autorização que aguardavam decisão. O sistema Radcom (Rádios Comunitárias) daquele Ministério acusava, entre os dias 3 e 25 de junho de 2005, a existência de nove emissoras autorizadas e $19 \mathrm{em}$ processo de avaliação; $2^{\mathrm{a}}$ etapa - Elaboração de um banco de dados, com base nessa listagem, de 
informações complementares de dois comunicadores locais conhecidos e da lista telefônica. No final dessa etapa, foram identificadas 19 entidades, conseguiu-se contatar dez (53\%) mais uma localizada durante os contatos realizados; $3^{a}$ etapa - Visita às rádios, após prévia marcação, nos dias 19 e 20 de julho de 2005. Onze rádios comprometeram-se a enviar um ou dois radiocomunicadores para participar.

Territorialização: Foram plotadas, no mapa municipal, as áreas de abrangência das rádios e dos serviços de saúde. A formação dos grupos de trabalho foi feita com base no território comum a ambos, o que os integraria geograficamente e os inseriria na mesma realidade social. Ademais, permitiria que fossem criados embriões para eventual elaboração de projetos educativos conjuntos (Anexo II).

\section{Descrição das oficinas}

Iniciavam-se com uma conversa acerca das relações entre a pintura, charge ou caricatura escolhida e o tema. Em seguida, divididos em cinco grupos de cerca de dez pessoas participantes, acompanhados de monitores que circulavam alternadamente entre eles, tinham como tarefa ler o capítulo da novela e o excerto do texto acadêmico, anteriormente programado como leitura complementar. Para que os textos representassem mais que simples informação, solicitou-se a elaboração de argumentos pró e contra as posições ali expressas. Esse mecanismo colaborou na percepção das diferenças de entendimento entre eles e naquelas presentes no momento da relação funcionários/comunidade.

Terminada a leitura, abria-se um tempo para: homogeneização do entendimento, identificação de dúvidas, elaboração dos argumentos (pró e contra sobre o texto), a possível relação entre a novela e o dia-a-dia, e a apresentação da plenária.

Após um intervalo, os trabalhos reiniciavam com a leitura da poesia, da parábola ou audição da música.

A plenária compunha-se das apresentações, seguida de discussões mediadas por um dos coordenadores.

Ao longo das oficinas, eram feitas avaliações dialogadas, a fim de permitir correções do processo. No encontro final, optou-se por formalizar a avaliação por meio de um questionário ordenado em três núcleos: Material e organização das oficinas; aprendizagem; diálogo e participação.

\section{Avaliação}

A avaliação contou com questões abertas sobre as oficinas, seu material e a incorporação de conhecimentos. A estratégia para reunir as observações, por critérios de sentido, foi a análise de conteúdo, utilizada em pesquisas qualitativas. Bardin (1979) aponta que se trata de um conjunto de técnicas de análise de comunicação destinadas a obter, por procedimentos sistemáticos e objetivos de descrição do conteúdo das mensagens, indicadores (quantitativos ou não) que permitam inferência de conhecimentos relativos às condições de produção/recepção destas mensagens. Do ponto de vista operacional, a análise de conteúdo relaciona as estruturas semânticas gerais do texto (significantes) com a estrutura dos significados, menos evidente, obtida pela compreensão dos fatores psicossociais, culturais e sociais em que a mensagem foi produzida. No questionário foi utilizada, basicamente, a análise de expressão.

Trabalhou-se, também, com a perspectiva que Bordieu (1972) deu à noção de "habitus", ligada à escolha do conceito do cotidiano como nexo do trabalho, e segundo a qual a identidade de condições de existência tende a produzir sistemas de avaliações semelhantes. Desta forma, cada pessoa, ainda que não saiba ou não queira, tem suas ações produzidas dentro de um contexto social, do qual não é a produtora isolada nem possui domínio completo.

\section{Avaliação dos participantes}

As respostas estratificadas, segundo os critérios apontados, demonstraram - salvo algumas especificidades ligadas à natureza do trabalho -, o amálgama de significados compartilhados. Desta forma não houve possibilidade de recuperar, na maior parte das respostas, as distinções iniciais entre radialistas e servidores. 


\section{Núcleo 1 - Material e Organização das Oficinas}

Novela: Dois aspectos foram os mais citados: - similaridade da linguagem e da ação dos usuários dos serviços: "... os fatos são como realmente acontece no dia-a-dia", "é como a maioria das pessoas que atendemos realmente pensa"; - papel na aprendizagem: "é boa e de fácil compreensão, melhor ainda quando se ouve o $\mathrm{Cd}$, parece estar vivendo a radionovela", "de ótima qualidade e linguagem de fácil entendimento", "Foi uma forma ótima de passar informações, ... para um processo educativo... ". Além disso, foram apontadas sugestões como - aumento da história de forma que não "ficasse só entre duas famílias".

Uma observação destacou-se das demais: "não dá para perceber muita diferenciação de linguagem entre as famílias". A crítica explicitou uma das intenções desse material, qual seja buscar demonstrar que, apesar de estilos de vida diferentes, ao discutir-se saúde, algumas posturas são semelhantes.

Textos científicos: buscaram homogeneizar o conhecimento técnico. Foram organizados excertos de trabalhos acadêmicos. Seu papel ficou ilustrado em frases como: "fáceis de ler e entender", "atuais e de boa qualidade", "... gostosos de ler e reler".

Músicas, poesias e pinturas: Propunham-se a expressar os temas em outras esferas da manifestação humana. A música foi a arte mais próxima e de mais fácil acesso: "falam da realidade em linguagem popular", "... a música alegra nossa vida e nos deixa mais animados". Uma (das) participante(s) elaborou paródias para os demais temas a partir da oficina sobre aids, que eram apresentadas no final dos encontros e foram gravadas em estúdio para eventual utilização em trabalhos com a comunidade. As canções apresentadas eram de vários estilos: "... as antigas têm mais qualidade", "bem escolhidas principalmente O Pulso", "a Marvada Pinga!!! Foi a melhor!!!!". Dois outros registros indicam a penetração da escolha: "poderia ter mais", "ótimas, acredito que podem ser utilizadas por nós em grupos de orientação pacientes/cuidadores".

Quanto às poesias, as referências foram ao lirismo e beleza. Por exemplo, frases como: " ... capaz de transmitir a idéia, por mais dura que seja, com suavidade..."; "são lindas.... nos ensinam a viver melhor", "...utilizando uma linguagem metafórica, traduz de forma mais suave (ou não) o que podemos estar comunicando...". Algumas manifestações identificaram a conexão com o tema: "bem escolhidas, relatando fatos do cotidiano, fazendo ligações com o texto informativo e a radionovela", "bem escolhidas aprofundando o entendimento dos temas abordados". Poucas registraram problemas, como: "algumas muito eruditas demais... poesia tem que tocar a alma".

Em relação às pinturas, caricaturas e charges, preponderaram respostas sobre o impacto visual causado. Um pequeno número de pessoas comentou: “... em primeira mão rodei o livro para ver as pinturas, me impressionou a capa", "um simples desenho que nos faz viajar no pensamento". Poucas estabeleceram conexão com o temário: "... de acordo com os assuntos...", "lindas, de acordo com o tema".

Trabalho em grupos e plenárias: Abrigaram os momentos de interação. Os participantes da Secretaria valorizaram a descoberta de parceiros internos: "bom porque a gente se conhece mais e percebe as idéias de cada um...", "percebi que todos enfrentamos problemas diários e juntos poderemos fazer a diferença...", "profissionais de vários setores, falando de igual para igual o mesmo assunto". Registraram a possibilidade de discordar sem gerar impasses: "Foram ricas e democráticas, todos nós tivemos oportunidade de expor nossas convicções e a troca de idéias é fundamental para o crescimento humano", "... temos opiniões diferentes mas pudemos chegar a um finalmente".

Outro aspecto abordado: "foi um aprendizado...", "foram de muita ajuda no sentido de ampliar meus conhecimentos". Referências críticas estiveram presentes: "os temas envolvidos foram bem colocados, mas com pouco tempo para uma discussão mais profunda...", "no início do trabalho, achei que estávamos meio sem rumo...", "os textos já deveriam ser lidos em casa e trazidos com anotações para discutir em grupo. Ganharíamos tempo para mais discussão e plenária mais elaborada".

Carga horária: As observações foram majoritariamente a favor de sua ampliação: "... poderia ser o dia todo", "precisaria ser aumentada para que nos aprofundássemos mais em cada tema...".

Estrutura: As respostas versaram sobre: a distância, próxima para alguns, "fora de mão" para a maioria; o espaço "local com salas mais apropriadas"; acerca dos equipamentos "maior apoio em relação a material, micro, datashow, som etc.", e a indicação de falhas relacionadas ao café: "... poderia 
ser melhor o local e o lanche". A melhora no lanche foi obtida com o compartilhamento de sanduíches, bolachas e bolos trazidos de casa. Essa alternativa indicou, à coordenação, relação positiva com os objetivos do projeto.

Temas: "ligados a realidade das rádios comunitárias, a comunidade pobre...", " pertinentes à nossa realidade", "envolver também temas sociais, pois encontramos isso dentro das UBS".

\section{Núcleo 2 - Aprendizagem}

Este núcleo tratou da aquisição de conhecimentos ou habilidades e sobre as possibilidades de sua utilização no cotidiano. Na pergunta - sobre o que foi mais importante para o aprendizado, identificaramse: - respostas que valorizaram o contato ("ver que em outros locais tem gente que pensa como você...", "o intercâmbio com as rádios comunitárias, numa linguagem comum a todos"); - a possibilidade de troca nos grupos e plenárias (" ... a oportunidade de expor minhas idéias à análise dos colegas e de ouvir o pensamento alheio que mesmo que seja contrário sempre acrescenta algo valioso", "pude expressar melhor meu pensamento"); - as lacunas de informação ("... para mim tudo foi aprendizado muito bom, deu para tirar muitas dúvidas...", "tudo tirou muitas dúvidas sobre o SUS e várias doenças..." , "... receber novas diretrizes para argumentar sobre certos assuntos com os usuários...").

Quanto à contribuição das oficinas para o dia-a-dia, a intenção foi contemplar os interesses do gestor e apreender o que Morin (2003) denominou de conhecimento pertinente. Algumas das respostas: “... já mudaram a forma em que me expresso nos grupos com a comunidade onde trabalho", "a forma de transmitir uma informação à população, respeitando sempre a cultura de cada um", "passar meus aprendizados para meus amigos de trabalho, para meus clientes, familiares e colocar de maneira descontraída, com conversas diárias sobre prevenção, conscientização...". Uma exceção apontou: “... no meu local de trabalho é muito difícil colocar as idéias que tenho (projetos) em prática. Ninguém quer... ter que quebrar a rotina, muito menos ser cobrado, dialogar, planejar...".

\section{Núcleo 3 - Diálogo e participação}

Comunicação: Parte das respostas indicou uma necessidade a ser contornada ("só pode vingar no momento em que a chefia e a unidade como um todo se proponham...", "penso em convencer a minha chefe...", "discutir frente à chefia e estudar um meio de passar para os usuários..."). Registrouse a possível dificuldade da nova abordagem: "acho que no início como todo trabalho vai ser bem difícil, mas depois que todos sentirem firmeza no nosso serviço...". Outros sugeriram criar novos espaços de comunicação e ampliar a relação com as rádios: “Conhecer uma rádio próxima do trabalho... levando pacientes para fazer depoimentos", "em parceria com a rádio comunitária, abordando temas e pesquisas (sugestão dos ouvintes) com horário estipulado". Ocorreram manifestações relacionadas às equipes, rádios e comunidade ("promovendo encontros entre equipes de saúde e rádio, visitas de uma ao outro...", "nas unidades e comunidades através de um calendário comum com assuntos diversos...").

A utilização da radionovela teve destaque: "escolher um tema e montar uma radionovela, com atores do nosso grupo como personagens, gravar e enviar para rádio...". Houve interesse de uma dentista em criar um capítulo sobre saúde bucal.

Conselho Gestor: Como a formação dos Conselhos era recente, existiam muitas dúvidas sobre seu papel. A visão genérica predominou: "ainda não sabemos muito sobre o Conselho Gestor...", " ... não que a proposta não seja ótima, mas... ainda tem muita coisa para mudar...".

Poucos valorizaram sua existência: "são meios de intercâmbio entre a comunidade e os gestores de saúde, são canais importantes de diálogo e reivindicação",

Por fim, foram estimulados a comentar a frase de Rubem Alves (Alves, Dimenstein, 2003, s/p):

Comunicar é a arte de fazer que uma idéia tenha vida.

Depois de plantada na cabeça de uma pessoa

ela desce para o coração e começa a procriar.

Só procriamos idéias que são amadas.

E o que elas procriam são novas relações. 
Explicitaram-se os sentimentos despertados pelo trabalho: "as novas relações procriam... penso que as amadas também podem procriar...", "... a partir do momento em que a idéia é aceita, ela começa a fazer parte da vida do indivíduo... e quando isso acontece o corpo e mente absorve...". Em relação entre ideias e ação: "... que sejam úteis precisam ser passadas à frente, informadas a outras pessoas, multiplicadas", "... no meu modo de ver temos que agir, fazendo com que as pessoas tenham idéias positivas em relação à saúde..."; " uma semente, bem semeada, cultivada...tenho muito orgulho de ser essa semente", ou ainda "reflete toda nossa vivência neste curso... Para trazer o melhor de nosso conhecimento para quem não os tem e aprender com quem nos pode ensinar....".

Avaliação da coordenação

Sobre as oficinas e a participação

A diversidade de materiais (o estímulo à manifestação,), a valorização do relato de experiências e a garantia da palavra criaram, nas oficinas, um clima favorável às trocas, ao aprendizado e entrosamento, impressão corroborada pela opinião dos participantes. Uma observação que respalda a afirmação acima foi a percepção de que o diálogo, nem sempre fácil entre pessoas de níveis diferentes de escolaridade, foi possível pela oportunidade de se utilizar a fala de "terceiros", os personagens.

Um grande "nó" foi a inconstância na participação dos radiocomunicadores, que dificultou a formação dos grupos de trabalho, com decorrências negativas para o processo educativo com a comunidade. Dentre os fatores que podem explicá-la e devem ser considerados em futuras experiências, destaque-se: coincidência de horário com outros vínculos de trabalho dos radialistas; falta de ajuda de custo para o deslocamento; receio de exposição, tendo em vista a perseguição da Anatel às emissoras da Grande São Paulo, especialmente as de Guarulhos, pela localização próxima do aeroporto, entre outros.

Enquanto isso, os funcionários da saúde, liberados do ponto, assumiram compromisso com a presença e envolvimento com o projeto, como ilustra a disposição em contatarem as rádios faltantes, para que, mesmo sem a presença nas oficinas, pudessem engajar-se nas propostas de trabalho com a comunidade.

As primeiras oficinas serviram para que a equipe de coordenação percebesse a necessidade de introduzir conceitos, tanto de disciplinas sociais como da área médica, o que foi feito pelo mediador da plenária com a finalidade de facilitar o processo de comunicação.

\section{Sobre o projeto e suas possibilidades}

O desenho do projeto considerou o caráter ampliado do conceito de saúde e o potencial articulador desenhado pelo SUS. Sua contribuição considerou a ideia de que todo prestador de serviço presente num mesmo território possa se relacionar, formando redes institucionais que interajam com a comunidade de forma técnica, ao mesmo tempo, amigável, respeitosa aos saberes de outra origem e solidária com os movimentos de construção da cidadania. Segundo Teixeira (1997), espera-se que, como instrumento de transparência e participação popular, as práticas de comunicação em saúde gerem um comportamento participativo pelo qual se daria o controle social do sistema. Buscando uma nova forma de conceituar a possibilidade de abertura de diálogo proporcionado por esta visão de comunicação, o autor aponta que a participação não se restringe apenas aos aspectos quantitativos do consumo, cuja multiplicação e distribuição adequada garantiriam a satisfação das necessidades de saúde, mas também nos aspectos qualitativos que embasam os atos técnicos, as definições gerenciais frente às escolhas técnicas e o caráter circunstancial e histórico das ações e das necessidades de saúde.

A metodologia permitiu que não se caminhasse na direção da normalização da vida, o que parece ter gerado uma maior possibilidade de aproximação entre os dois grupos e (mesmo) com a coordenação. Pareceu adequar-se ao que escreveu Cora Coralina: "Feliz aquele que transfere o que sabe e aprende o que ensina".

Outra preocupação que também pareceu ter sido superada foi a da aparente dicotomia entre informação técnica e possibilidade de ação no dia-a-dia. Buscou-se, ao longo do trabalho, mostrar que a divisão entre a prática - usada como o fazer utilitário, sem reflexão -, e a teoria - definida como um 
conjunto de abstrações compreendidas por poucos - unem-se no exercício da práxis, esta podendo ser entendida como ações orientadas por uma interpretação do mundo (teoria) que gera, no fazer, uma intencionalidade capaz de produzir mudanças (Vasquez, 1978).

Dentre os objetivos aparentemente não atingidos e de grande importância na conquista de resultados, pode-se citar a inexistência de mecanismos para a manutenção da relação servidores-radialistas. Movimentos como estes precisam de retaguarda e proteção institucional (no caso dos serviços de saúde) e confiança nas ações governamentais (no caso das rádios comunitárias). Já que estes tinham dificuldade em compreender um poder público que, por um lado, chama e respeita, enquanto, por outro, lacra e sequestra os equipamentos.

O projeto demonstrou potencial para contribuir com o processo de educação e participação popular, e duas frases expressam essa dimensão: uma de Pierre Levy - "A verdadeira inteligência do homem consiste em tornar sua sociedade inteligente. Ela se exprime nas mensagens (que se endereçam a outros), linguagens (cuja natureza é a de ser um laço), nas ferramentas (suscetíveis de transmissão, de melhoria, de combinação e de utilização coletiva), nas instituições (que concernem ao coletivo ou o organizam). A inteligência humana trabalha na conexão" (Levy, 2000, p.37); a outra, de um dos participantes: "Mobilização e conscientização sobre a saúde".

A maior parte dos comentários está identificada com verbos que indicam uma avaliação positiva do trabalho, o que pode ser fruto de análise temporalmente concomitante ao seu encerramento; mas um importante aviso deve ser registrado: o desenvolvimento e a efetividade de projetos como este exigem o compromisso dos gestores.

\section{Colaboradores}

Os autores participaram igualmente da elaboração e redação do manuscrito.

\section{Referências}

ALVES, R.; DIMENSTEIN, G. Fomos maus alunos. 3.ed. São Paulo: Papirus, 2003. (contracapa)

BARDIN, L. Análise de conteúdo. Lisboa: Edições 70, 1979.

BOURDIEU, P. Esquisse de une théorie de la pratique. Paris: Librairie Droz, 1972.

DOMINGUES, J.M. Vida cotidiana, história e movimentos sociais. Dados - Rev. Cienc. Soc., v.46, n.3, p.461-90, 2003.

LEVY, P. A conexão planetária: o mercado, o ciberespaço, a consciência. São Paulo: Editora 34, 2000.

MORIN, E. Os sete saberes necessários à educação do futuro. São Paulo: Cortez/ Unesco, 2003.

PITTA, A.M.R.; OLIVEIRA, V.C. Estratégias de comunicação frente ao desafio do Aedes aegypti no Brasil. Cienc. Saude Colet., v.1, n.1, p.137-46, 1996.

TEIXEIRA, R.R. Modelos comunicacionais e práticas de saúde. Interface - Comunic., Saude, Educ., v.1, n.1, p.7-40, 1997.

VALLA, V.V. Sobre a participação popular: uma questão de perspectiva. Cad. Saude Publica, v.14, supl.2, p.7-18, 1998.

VÁSQUEZ, A.S. Filosofia da praxis. São Paulo: Editora Paz e Terra, 1978. 
Este trabalho refere-se à experiência desenvolvida no município de Guarulhos, sob o patrocínio do Ministério da Saúde, com o objetivo de envolver radiocomunicadores no processo educativo em saúde. Organizaram-se oficinas de trabalho com a participação de funcionários dos serviços municipais de saúde e de radialistas das rádios comunitárias das mesmas áreas de abrangência, para reflexão, discussão e elaboração de ações conjuntas sobre temas de saúde. Desenvolveu-se metodologia que articulou, além de textos acadêmicos, outros tipos de linguagem como pintura, música, radionovela, poesia etc., na abordagem dos assuntos. A avaliação final constou de um questionário preenchido pelos participantes e a análise das respostas indicou tratar-se de uma metodologia compatível com os objetivos de alcançar envolvimento e desenvolver parcerias entre comunicadores, serviços de saúde e comunidade.

Palavras-chave: Comunicação. Saúde. Rádios comunitárias. Educação.

\section{An experience in communication and health}

This paper reports on an experience developed in the municipality of Guarulhos, under the sponsorship of the Ministry of Health, in which the aim was to involve radio broadcasters in the health education process. Workshops on health subjects were organized with the participation of municipal healthcare service employees and community radio broadcasters with the same area of coverage, for reflection, discussion and elaboration of joint actions. The methodology developed brought together not only academic texts but also other types of language such as painting, music, radio serials, poetry, etc, to deal with these subjects. The final evaluation consisted of a questionnaire filled out by the participants. Analysis on the responses indicated that this methodology was compatible with the aims of achieving involvement and developing partnerships between communicators, healthcare services and the community.

Keywords: Communication. Health. Community radio stations. Education.

\section{Una experiencia en comunicación y salud}

Este trabajo se refiere a la experiencia desarrollada en el municipio de Guarulhos, estado de Sao Paulo, Brasil, bajo el patrocinio del Ministerio de la Salud, con objeto de involucrar a radiocomunicadores en el proceso educativo en salud. Se organizaron oficinas de trabajo con la participación de funcionarios de los servicios municipales de salud y de profesionales de las radios comunitarias de las mismas áreas que comprenden reflexión, discusión y elaboración de acciones conjuntas sobre temas de salud. Se ha desarrollado una metodología que articula, además de textos aoadémicos, otros tipos de lenguaje como pintura, música, radionovela, poesía etc en el planteamiento de los asuntos. La evaluación final consistió en un cuestionario respondido por los participantes; y el análisis de las respuestas indicó que se trata de una metologia compatible con los objetivos de obtener adhesión y desarrollar asociación entre comunicadores, servicios de salud y comunidad.

Palabras clave: Comunicación. Salud. Radios comunitarias. Educación. 
ANEXO I - Programação geral das Oficinas

\begin{tabular}{|c|c|c|c|c|}
\hline Oficina & $\begin{array}{c}\text { Data } \\
\text { indicativa }\end{array}$ & $\begin{array}{l}\text { Horário } \\
\text { sugerido }\end{array}$ & Tema & Suportes/Conteúdos \\
\hline \multicolumn{5}{|c|}{ Oficina de abertura e reconhecimento dos grupos } \\
\hline 01 & $16 / 09$ & $8 \mathrm{~h} 30$ às12h30 & $\begin{array}{l}\text { SUS, Saúde e } \\
\text { Comunicação }\end{array}$ & $\begin{array}{l}\text { Pintura - A escola de Atenas (Rafael) } \\
\text { Crônica: O menino do dedo roxo (Lourenço Diaféria) } \\
\text { Textos: } \\
\text { 1- Balanço de experiências de controle } \\
\text { social, para além dos Conselhos e Conferências do Sistema } \\
\text { Único de Saúde brasileiro: construindo a possibilidade de } \\
\text { participação dos usuários (Côrtes, S.M.V.) } \\
\text { 2- Trechos da Lei no } 8080 \\
\text { 3- Trechos da Lei no } 8142 \\
4 \text { - } 12^{\text {a }} \text { Conferência Nacional de Saúde Eixo Temático X- } \\
\text { Comunicação e Informação em Saúde } \\
\text { Música - Boas vindas (Caetano Veloso) }\end{array}$ \\
\hline \multicolumn{5}{|c|}{ Oficinas de interação e aprofundamento } \\
\hline 02 & $21 / 09$ & $8 h 30$ às12h30 & $\begin{array}{l}\text { Saúde- } \\
\text { doença }\end{array}$ & $\begin{array}{l}\text { Pintura - Vida e morte (Gustav Klimt ) } \\
\text { Radionovela: Almoço de domingo - cap.1 (Luiz Meneguetti) } \\
\text { Textos: } \\
\text { 1- A doença (Berlinguer, G.) } \\
\text { 2- Saúde-doença: uma concepção popular de etiologia. } \\
\text { Mynaio, M.C.S. } \\
\text { Música - Pulso - Titãs }\end{array}$ \\
\hline 03 & $30 / 09$ & $8 h 30$ às12h30 & $\begin{array}{l}\text { Atenção à } \\
\text { saúde }\end{array}$ & $\begin{array}{l}\text { Pintura - Enfermaria do Hospital de Arles (Van Gogh) } \\
\text { Radionovela: Almoço de domingo - cap.2 (Luiz Meneguetti) } \\
\text { Texto: A gestão dos serviços públicos de saúde: } \\
\text { características e exigências (Dussault, G.) } \\
\text { Poesia - Ode às muletas (Cora Coralina) }\end{array}$ \\
\hline 04 & $05 / 10$ & $8 h 30$ às12h30 & $\begin{array}{l}\text { Modelos } \\
\text { de atenção }\end{array}$ & $\begin{array}{l}\text { Pintura - Tem cabeça, mãos, pés e coração (Paul Klee) } \\
\text { Radionovela: Almoço de domingo - cap.3 (Luiz Meneguetti) } \\
\text { Texto: Modelos de atenção voltados para a qualidade, } \\
\text { efetividade, equidade e necessidades prioritárias de saúde } \\
\text { (Teixeira, C.F.) } \\
\text { Poesia - Mãos dadas (Carlos Drummond de Andrade) }\end{array}$ \\
\hline \multicolumn{5}{|c|}{ Oficinas temáticas } \\
\hline 05 & $14 / 10$ & $8 \mathrm{~h} 30$ às12h30 & DST e Aids & $\begin{array}{l}\text { Pintura - Abraço (Egon Schiele) } \\
\text { Radionovela: Almoço de domingo - cap.4 (Luiz Meneguetti) } \\
\text { Textos: } \\
\text { 1- AIDS - Manual de Sobrevivência (http:// } \\
\text { openlink.br.inter.net/aids2- www.unaids.org/wad2004/ } \\
\text { report.htm; 3- www.aids.gov.br4; www.crt.saude.sp.gov.br) } \\
\text { Cordel - Paródia do mijador com mijador - CD Radialistas } \\
\text { contra AIDS }\end{array}$ \\
\hline 06 & $19 / 10$ & $8 \mathrm{~h} 30$ às12h30 & Tuberculose & $\begin{array}{l}\text { Pintura - Grupo do homem doente (Cândido Portinari) } \\
\text { Radionovela: Almoço de domingo - cap.5 (Luiz Meneguetti) } \\
\text { Texto: A tuberculose ao longo dos tempos (Gonçalves,H.) } \\
\text { Poesia - Pneumotórax (Manuel Bandeira) }\end{array}$ \\
\hline
\end{tabular}




\begin{tabular}{|c|c|c|c|c|}
\hline Oficina & $\begin{array}{c}\text { Data } \\
\text { indicativa }\end{array}$ & $\begin{array}{l}\text { Horário } \\
\text { sugerido }\end{array}$ & Tema & Suportes/Conteúdos \\
\hline \multicolumn{5}{|c|}{ Oficinas temáticas } \\
\hline 07 & $26 / 10$ & 8h30 às12h30 & Hipertensão & $\begin{array}{l}\text { Pintura - Mulher chorando (Pablo Picasso) } \\
\text { Radionovela: Almoço de domingo - cap.6 (Luiz } \\
\text { Meneguetti) } \\
\text { Textos: } \\
1 \text { - Cultura, Saúde \& Doenças (Helman, C.G.) } \\
2 \text { - Gestão de saúde: curso de aperfeiçoamento para } \\
\text { dirigentes municipais de saúde: programa de educação a } \\
\text { distância (Fiocruz) } \\
3 \text { - www.manuais de cardiologia.med.br/hás } \\
\text { Poesia - Não comerei do alface a verde pétala... (Vinicius } \\
\text { de Moraes) }\end{array}$ \\
\hline 08 & $09 / 11$ & 8h30 às12h30 & Diabetes & $\begin{array}{l}\text { Charge sem título de João Bosco de Azevedo } \\
\text { Radionovela: Almoço de domingo - cap.7 (Luiz } \\
\text { Meneguetti) } \\
\text { Texto: Consenso Diabetes (http//www.diabetes.org.br) } \\
\text { Parábola: O discurso e a prática (Org. Alexandre Rangel. Ed. } \\
\text { Leittura - 2002) }\end{array}$ \\
\hline 09 & $11 / 11$ & 8h30 às12h30 & Vacinação & $\begin{array}{l}\text { Ilustração do acervo da Casa de Oswaldo Cruz da Fundação } \\
\text { Oswaldo Cruz (A Revolta da Vacina da Varíola às } \\
\text { Campanhas de Imunização (Rio de Janeiro, 1994). } \\
\text { Radionovela: Almoço de domingo - cap.8 - Luiz } \\
\text { Meneguetti } \\
\text { Texto: Qual a cobertura vacinal real? Informe Unifesp - } \\
\text { Moraes, J.C. et al. } \\
\text { Mensagem: Betinho - A criança é coisa séria }\end{array}$ \\
\hline 10 & $16 / 11$ & $8 h 30$ às12h30 & $\begin{array}{l}\text { Gravidez na } \\
\text { adolescência }\end{array}$ & $\begin{array}{l}\text { Madona - ilustração de Reginaldo Fortuna } \\
\text { Radionovela: Almoço de domingo - cap.9 (Luiz } \\
\text { Meneguetti) } \\
\text { Textos: } \\
1 \text { - Gravidez de adolescência: uma questão social (Souza, } \\
\text { I.F.) } \\
2 \text { - Gravidez na adolescência (Paulics, V.) } \\
\text { Música: Ligeiramente grávida (Rita Lee) }\end{array}$ \\
\hline 11 & $18 / 11$ & $8 h 30$ às12h30 & $\begin{array}{l}\text { Álcool e } \\
\text { drogas }\end{array}$ & $\begin{array}{l}\text { Ilustração de Luís Eugênio Quintão Guerra } \\
\text { Radionovela: Almoço de domingo - cap.10 (Luiz } \\
\text { Meneguetti) } \\
\text { Texto: A política do Ministério da Saúde para a atenção } \\
\text { integral a usuários de álcool e outras drogas (2003) } \\
\text { Música: Marvada pinga (Rolando Boldrin) }\end{array}$ \\
\hline 12 & $23 / 11$ & 8h30 às12h30 & $\begin{array}{l}\text { Acolhimento } \\
\text { no SUS }\end{array}$ & $\begin{array}{l}\text { llustração do cartunista Laerte } \\
\text { Radionovela: Almoço de domingo - cap.11 (Luiz } \\
\text { Meneguetti) } \\
\text { Texto: Sobre a participação popular: uma questão de } \\
\text { perspectiva (Valla, V.V.) } \\
\text { Poema: } A \text { arte de ser feliz (Cecília Meireles) }\end{array}$ \\
\hline \multicolumn{5}{|c|}{ Oficina de encerramento } \\
\hline 13 & $25 / 11$ & $8 \mathrm{~h} 30$ às $12 \mathrm{~h} 30$ & Avaliações & \\
\hline
\end{tabular}


ANEXO II - Mapa da cidade de Guarulhos com a indicação das 11 rádios comunitárias do município que manifestaram interesse em participar das oficinas do projeto.

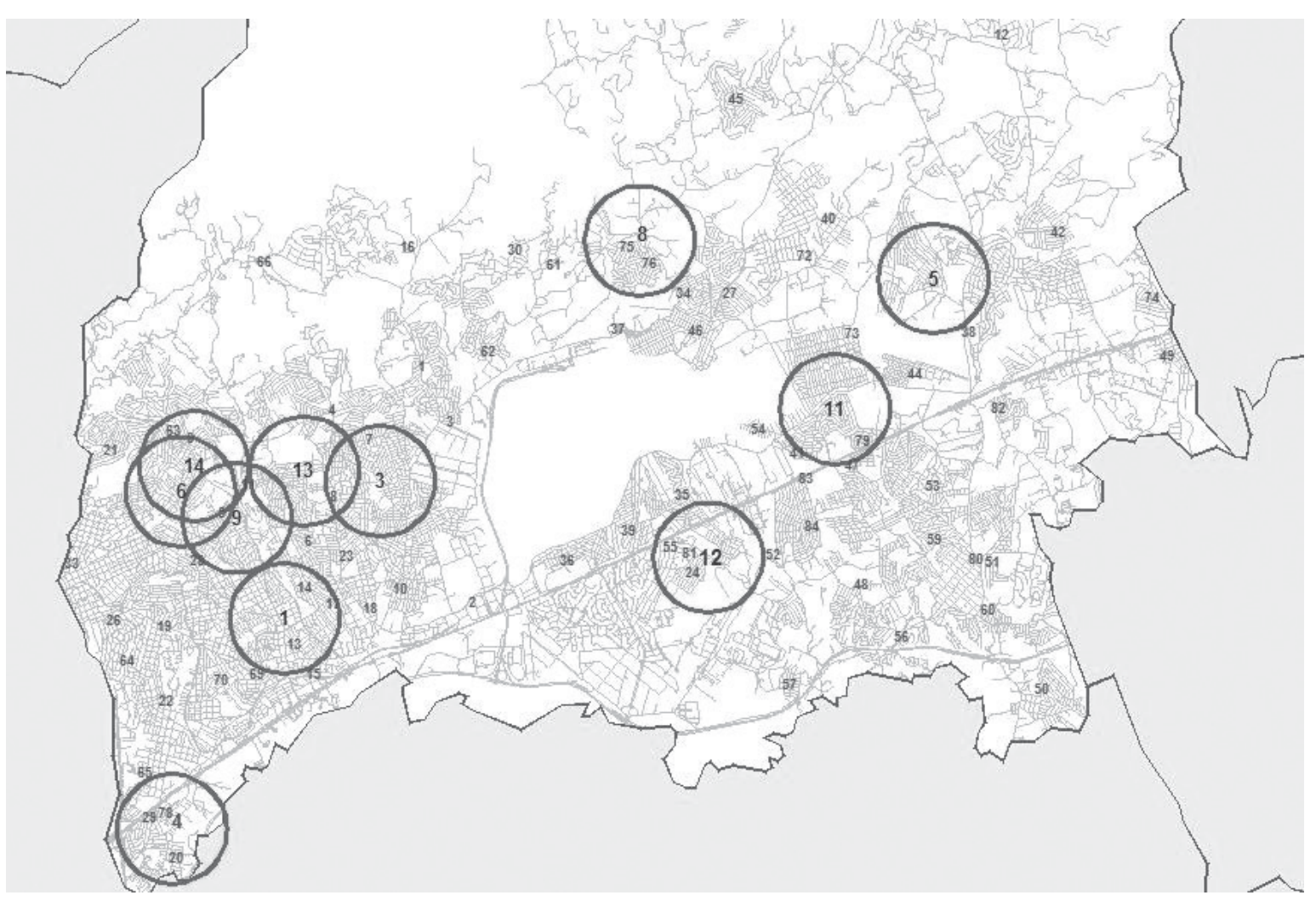

